\title{
Safety of adjuvant gemcitabine plus cisplatin chemotherapy in a patient with bilateral ureteral cancer undergoing hemodialysis
}

\author{
Yumiko Goto $^{1}\left[\mathrm{Kent}_{\mathrm{Kanao}}{ }^{2} \cdot \mathrm{Kazuhiro} \mathrm{Matsumoto}^{3} \cdot\right.$ Ikuo Kobayashi $^{4} \cdot \mathrm{Keishi} \mathrm{Kajikawa}^{4} \cdot$ Masafumi Onishi $^{1}$
}

Received: 25 November 2020 / Accepted: 7 April 2021 / Published online: 22 April 2021

(c) The Author(s) 2021

\begin{abstract}
An 80 year old Japanese man with bilateral ureteral cancer underwent laparoscopic bilateral nephroureterectomy and lymphnode dissection. The pathological stage of the left and right ureteral tumors was pT3pNOM0. He received two courses of adjuvant gemcitabine and cisplatin chemotherapy while undergoing hemodialysis. The standard dose of gemcitabine and $50 \%$ of the standard dose of cisplatin were administered on the same day. Hemodialysis was started $6 \mathrm{~h}$ after gemcitabine administration and $1 \mathrm{~h}$ after cisplatin administration. The side effects were evaluated according to the Common Terminology Criteria for Adverse Events v4.0. In the first course, Grade 4 side effects including leukopenia, neutropenia, and thrombocytopenia were observed. He was treated with granulocyte colony-stimulating factor and platelet transfusion. Because the second course was administered without reducing the doses, granulocyte colony-stimulating factor was administered prophylactically, and Grade 4 side effects were reduced to Grade 3. Gemcitabine plus cisplatin chemotherapy can be administered safely in a patient with advanced ureteral cancer undergoing hemodialysis by adequately managing adverse events.
\end{abstract}

Keywords Hemodialysis $\cdot$ Bilateral ureteral cancer $\cdot$ Gemcitabine plus cisplatin $\cdot$ Adjuvant chemotherapy

\section{Introduction}

In recent years, the incidence of malignant tumors among patients on maintenance dialysis is high, as the survival rate increases. Gemcitabine plus cisplatin (GC) chemotherapy, and dose-dense (high-dose) methotrexate, vinblastine, doxorubicin, and cisplatin (DDMVAC) chemotherapy, which is possible by the routine use of granulocyte colony-stimulating factor (G-CSF) are first-line chemotherapy options for advanced urothelial carcinoma [1,2]. The efficiency of GC

Yumiko Goto

yumiko@aichi-med-u.ac.jp

1 Department of Hospital Pharmacy, Aichi Medical University, 1-1 Yazakokarimata, Nagakute, Aichi 480-1195, Japan

2 Urology of Uro-Oncology, Saitama Medical University International Medical Center, 1397-1 Yamane, Hidaka, Saitama 350-1298, Japan

3 Department of Urology, Keio University School of Medicine, 35 Shinanomachi, Shinjuku-ku, Tokyo 160-8582, Japan

4 Department of Urology, Aichi Medical University School of Medicine, 1-1 Yazakokarimata, Nagakute, Aichi 480-1195, Japan is known to be almost the same as that of standard MVAC, and the safety and tolerability of GC is higher than that of MVAC [3].

There is no clear evidence on whether preoperative or postoperative chemotherapy for urothelial cancer is better. According to the guidelines for renal pelvic and ureteral cancer treatment established in 2014, postoperative adjuvant chemotherapy may be considered for $\geq \mathrm{pT} 3$ or $\mathrm{pN}+$ (recommended grade $\mathrm{C} 1$ ) renal pelvic and ureteral cancer [4], given that their organizations are similar to those of invasive bladder cancer.

The 2016 Renal Impairment Clinical Practice Guidelines suggest that up to $50 \%$ of the standard dose of cisplatin (CDDP) may be administered to patients undergoing hemodialysis (HD) because of its nephrotoxicity [5-7]. However, the available evidence for evaluating safety is limited, and to our knowledge, there is no case report of a patient who was administered adjuvant GC chemotherapy after bilateral nephroureterectomy. Herein, we report the case of a patient with bilateral ureteral cancer undergoing HD who was administered adjuvant GC chemotherapy. 


\section{Case report}

An 80-year-old Japanese man who underwent transurethral ureteral lithotripsy for a right lower ureteral stones at another hospital in 201X suffered a ureteral injury at that time. Postlithotripsy, he had microscopic hematuria for which he was followed up for 3 months. Following his presentation with gross hematuria for 1 month, he came to our hospital, and bladder cancer was diagnosed. Because of urothelial carcinoma in situ (CIS) after transurethral resection of the bladder tumor (TURBT), Bacille Calmette-Guérin (BCG) was injected into his bladder six times from August $201 \mathrm{X}+1$. In $201 \mathrm{X}+2$, a $3 \mathrm{~mm}$ papillary tumor recurred in the neck of the bladder [papillary urothelial carcinoma, high-grade $(\mathrm{G} 2>3)$, and non-invasive]. In October $201 \mathrm{X}+3$, computed tomography findings were suggestive of bilateral ureteral cancer; bilateral laparoscopic nephroureterectomy and lymph-node dissection were performed (Fig. 1). The histopathological examination of the right and left ureteral tumors showed urothelial carcinoma high-grade pT3 with no lymph-node metastasis (Fig. 2). After HD initiation, 2 courses of postoperative GC chemotherapy were administered. Based on the pharmacokinetics of CDDP and gemcitabine (GEM), we used the following regimen. On day 1 , he was administered $1000 \mathrm{mg} / \mathrm{m}^{2}$ of GEM (100\% of normal dose) dissolved in $100 \mathrm{~mL}$ of saline intravenously over $30 \mathrm{~min}$, after which $35 \mathrm{mg} / \mathrm{m}^{2}$ of CDDP (50\% of normal dose) in $250 \mathrm{~mL}$ of saline was administered. The total volume of water was $650 \mathrm{~mL}$, and diuretics were not used. HD was started $6 \mathrm{~h}$ after GEM infusion, $1 \mathrm{~h}$ after CDDP infusion, and it lasted
$4 \mathrm{~h}$. HD was conducted 3 times per week. On days 8 and 15 , he received $1000 \mathrm{mg} / \mathrm{m}^{2}$ of GEM. To prevent nausea, aprepitant, dexamethasone, and palonosetron hydrochloride were administered.

In the first course, grade 4 leukopenia, neutropenia, and thrombocytopenia occurred. Therefore, GEM was discontinued on day 15 because of bone marrow toxicity. G-CSF and platelet transfusion were administered. Although febrile neutropenia was not observed during the first treatment course, G-CSF was administered proactively on days 5-7 during the second course for prevention of febrile neutropenia. GEM was discontinued on day 15 because of thrombocytopenia; however, neutropenia remained at Grade 3 (Fig. 3). All nonhematological toxicities, such as nausea, fatigue, anorexia, and fever, were Grade 0 throughout all the treatment courses. The patient underwent cystectomy, because multiple recurrent of bladder cancer was observed in the remaining bladder after the two courses of adjuvant GC chemotherapy.

Cystectomy was performed in this patient, because he was diagnosed with high-risk non-muscular invasive bladder cancer with CIS after the first TURBT, and recurrence was diagnosed despite the BCG injections after the first TURBT. The pathological examination of the resected bladder showed invasive urothelial carcinoma (Grade3) with CIS, after BCG and TURBT therapeutic status, pT2, ly0, v0, surgical margin is negative. No recurrence has been observed to date. The patient provided informed consent for the publication of this report and its supporting images. He was managed in accordance with the principles of the Declaration of Helsinki.
Fig. 1 Pre-nephroureterectomy contrast computed tomography showed bilateral ureteral cancer (arrows). Right central ureter (a). Right lower ureter (b). Left renal pelvis (c). Left lower ureter $(\mathbf{d})$
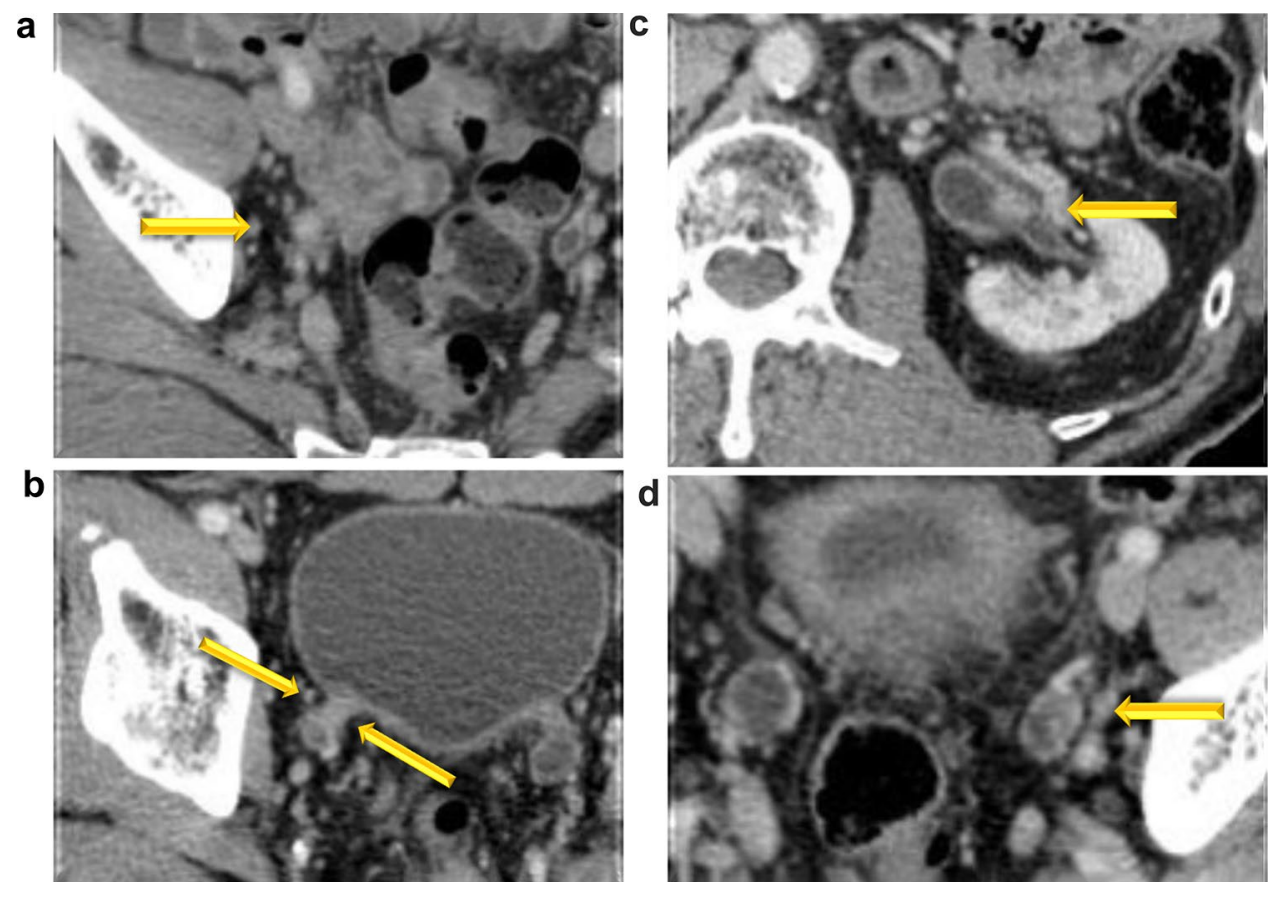
a

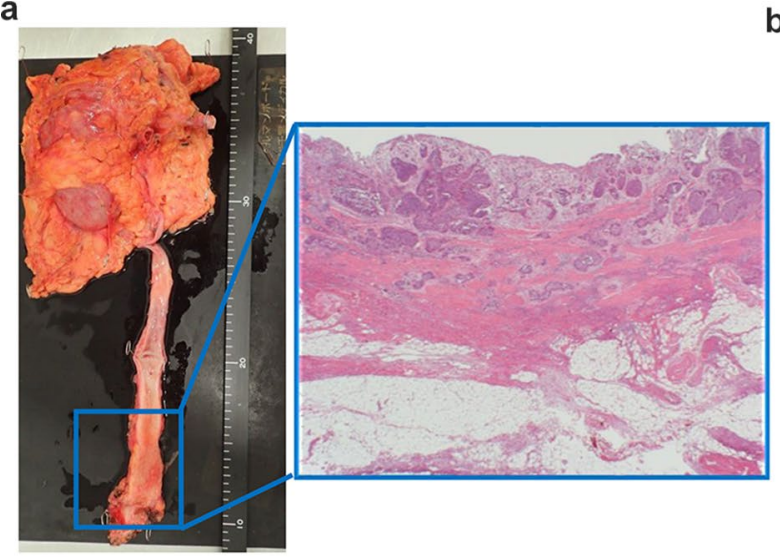

b

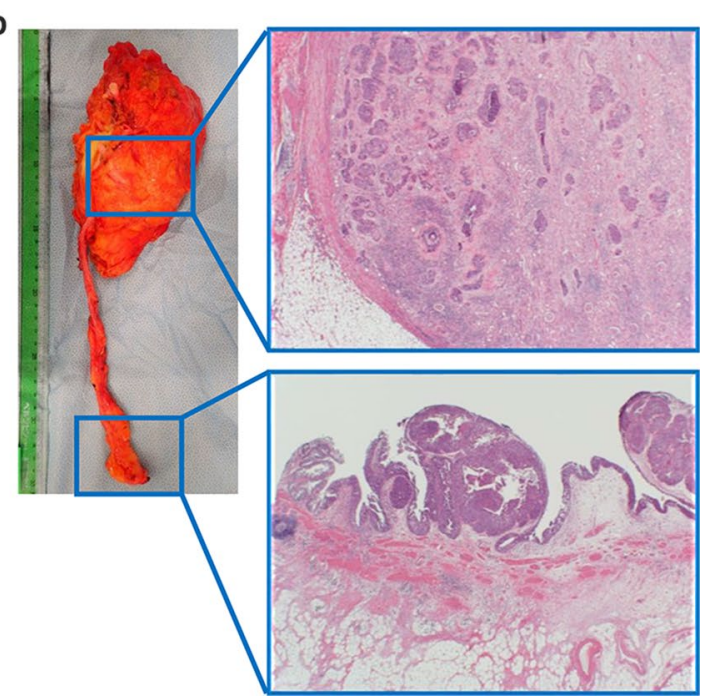

Fig. 2 Histopathological findings of the resected tumor of the renal pelvis and ureter. Right (a). Invasive urothelial cancer of high-grade pT3 with carcinoma in situ (CIS) observed from the middle to the lower part of the ureter. Left (b). Invasive urothelial cancer of highgrade pT3 with CIS was found in the left renal pelvis. CIS was also found in the ureter, which spreaded over almost the entire area

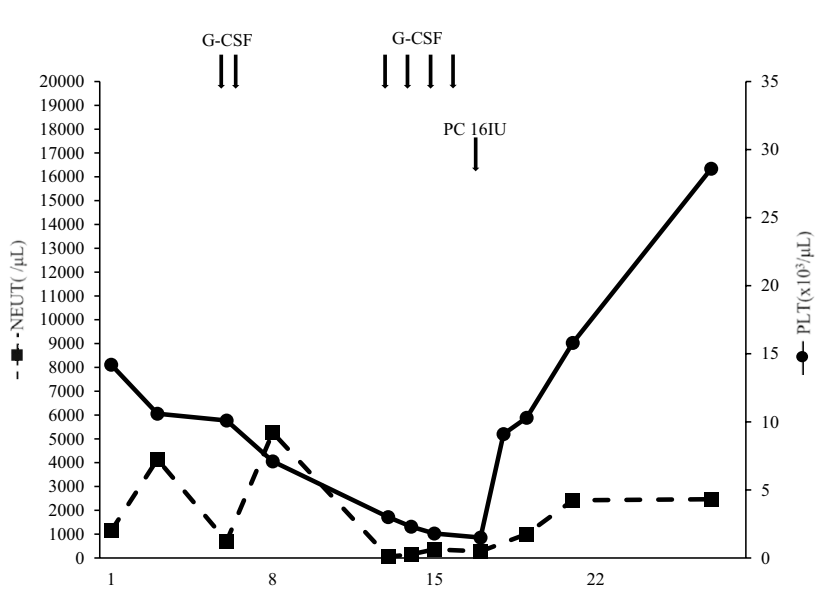

1 st cycle(day)

Fig. 3 Laboratory data obtained during the patient's clinical course. Data regarding neutrophils and platelets. Arrows indicate administered granulocyte colony-stimulating factor and platelet concentrates.

\section{Discussion}

We reported a patient who received adjuvant GC chemotherapy safely while undergoing HD. Adjuvant chemotherapy is an accepted standard of care for locally advanced upper urinary tract cancer, based on the result of the PUOT trial [8]; this trial showed that gemcitabine-platinum combination chemotherapy after nephroureterectomy improved disease-free survival significantly. However, given that CDDP is excreted by the kidneys, and it can destroy them,

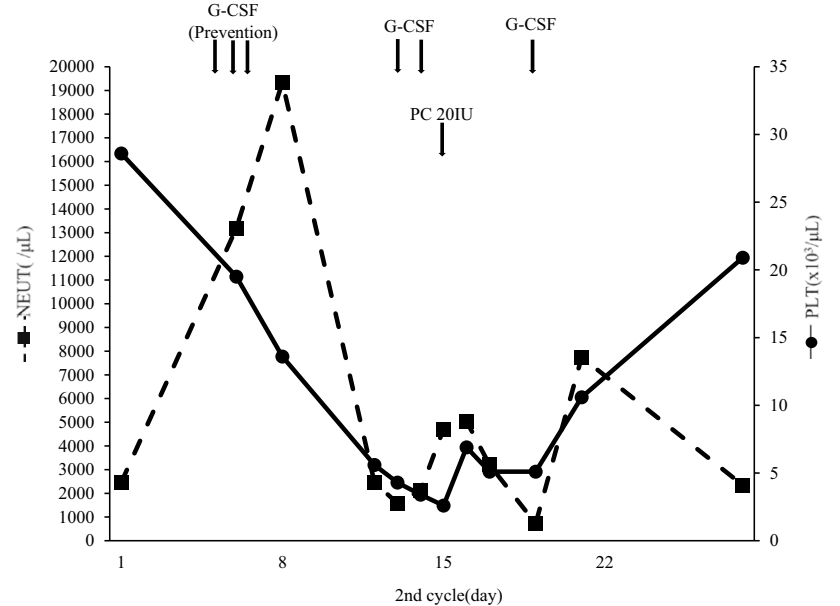

NEUT neutrophils, PLT platelet, G-CSF granulocyte colony-stimulating factor, $P C$ platelet concentrates, $I U$ international unit

it is used only for patients with good renal functions. When chemotherapy is administered in patients receiving HD, the drug doses and HD schedule are individualized. There is no established treatment regimen for GC in patients receiving $\mathrm{HD}$, and the appropriate dose and timing of each agent for these patients are unclear. There are some reports on urothelial carcinoma treated with CDDP-based chemotherapy in patients receiving HD. Chang et al. [9] carried out a study of 4 patients receiving HD who were treated with a GC regimen based on their experience, but the pharmacokinetics of the drugs were not analyzed. It 
is best to do careful therapeutic drug monitoring (TDM) and to optimize drug exposure, ensure efficacy, and reduce the risk of side effects $[10,11]$. However, a few studies have demonstrated the efficacy and safety of the GC regimen in patients receiving HD by properly monitoring the concentration of each drug. In this case, we had no time to prepare for the TDM of each drug. Therefore, we designed the dose of CDDP and GEM based on pharmacokinetics.

CDDP binds to blood plasma proteins, and bound CDDP exceeds $90 \%$ within a few hours after administration [12-14]. The area under the curve of free (unbound) CDDP is closely correlated with cytotoxicity, such as bone marrow toxicity, and other side effects [15, 16]. CDDP has a high protein binding rate, which is expected to rebound immediately after the elimination of free CDDP by HD [13]. Based on previous experience $[11,17]$, we reduced the dose of CDDP by $50 \%$ and performed HD $1 \mathrm{~h}$ later.

On the other hand, it was concluded that GEM administration in patients receiving HD is relatively safe [6]. GEM is rapidly metabolized by cytidine deaminase (found in great quantities in the liver, blood, and many tissues) to $2^{\prime}, 2^{\prime}$-difluorodeoxyuridine (dFdU), which is currently considered an inactive metabolite and which disappears from plasma [14, 18-20].

GEM is rapidly eliminated from plasma even in patients with renal dysfunction. There were no obvious differences in pharmacokinetic parameters, such as the elimination halflife of GEM $\left(\mathrm{t}_{1 / 2}\right)$, area under the concentration-time curve, and maximum GEM concentration between the patients on $\mathrm{HD}$ and those with normal renal functions. On the other hand, the levels of $\mathrm{dFdU}$ were constant until HD was initiated, because it was not excreted in urine depending on renal functions. As previously reported, the plasma level of $\mathrm{dFdU}$ is reduced by approximately $50 \%$ after one HD session [18] and is almost eliminated after 2-3 HD sessions. The same doses of GEM in this study are safe for use in HD and nonHD patients. Meanwhile, dFdU is not toxic, but the clinical effects of its accumulation in the body are unknown. Therefore, it is recommended to perform HD 6-12 $\mathrm{h}$ after GEM administration [18, 19].

Following these reasons, we administered a $100 \%$ dose of GEM and started HD $6 \mathrm{~h}$ after the administration.

After the administration, we did not monitor the blood concentration; frequent blood sampling and observation for side effects were performed. G-CSF and platelet transfusion were administered for neutropenia and thrombocytopenia, respectively.

Since surgery is the basic treatment for urothelial cancer, even a person with a normal renal function may have a unilateral kidney postoperatively, resulting in decreased renal function. Therefore, chemotherapy for patients with urothelial cancer having impaired renal function should be carefully considered. Adjuvant GC chemotherapy was safe for patients with impaired renal function receiving HD after bilateral nephroureterectomy like our patient. These findings may be similar in patients with chronic kidney disease or dialyzed patients. To confirm this, chemotherapy and its side effects should be monitored carefully in these patients in future studies.

In conclusion, adjuvant GC chemotherapy was administered safely in a patient with bilateral ureteral cancer undergoing HD by adequate management of the adverse events.

\section{Declarations}

Conflict of interest The authors declare that they have no conflict of interest.

Ethical approval All procedures performed in studies involving human participants were in accordance with the ethical standards of the institutional and/or national research committee and with the 1964 Helsinki declaration and its later amendments or comparable ethical standards.

Informed consent Informed consent was obtained from the patient included in the study.

Open Access This article is licensed under a Creative Commons Attribution 4.0 International License, which permits use, sharing, adaptation, distribution and reproduction in any medium or format, as long as you give appropriate credit to the original author(s) and the source, provide a link to the Creative Commons licence, and indicate if changes were made. The images or other third party material in this article are included in the article's Creative Commons licence, unless indicated otherwise in a credit line to the material. If material is not included in the article's Creative Commons licence and your intended use is not permitted by statutory regulation or exceeds the permitted use, you will need to obtain permission directly from the copyright holder. To view a copy of this licence, visit http://creativecommons.org/licenses/by/4.0/.

\section{References}

1. Flaig TW, Spiess PE, Agarwal N, Bangs R, Boorjian SA, Buyyounouski MK, Chang S, Downs TM, Efstathiou JA, Friedlander T, Greenberg RE, Guru KA, Guzzo T, Herr HW, Hoffman-Censits J, Hoimes C, Inman BA, Jimbo M, Kader AK, Lele SM, Michalski J, Montgomery JS, Nandagopal L, Pagliaro LC, Pal SK, Patterson A, Plimack ER, Pohar KS, Preston MA, Sexton WJ, Siefker-Radtke AO, Tward J, Wright JL, Gurski LA, Johnson-Chilla A (2020) J Natl Compr Canc Netw, version 3(18):329-354. https://doi.org/ 10.6004/jnccn.2020.0011

2. Bamias A, Dafni U, Karadimou A, Timotheadou E, Aravantinos G, Psyrri A, Xanthakis I, Tsiatas M, Koutoulidis V, Constantinidis C, Hatzimouratidis C, Samantas E, Visvikis A, Chrisophos M, Stravodimos K, Deliveliotis C, Eleftheraki A, Pectasides D, Fountzilas G, Dimopoulos MA (2013) Prospective, open-label, randomized, phase III study of two dose-dense regimens MVAC versus gemcitabine/cisplatin in patients with inoperable, metastatic or relapsed urothelial cancer: a hellenic cooperative oncology group study (HE 16/03). Ann Oncol 24:1011-1017. https:// doi.org/10.1093/annonc/mds583 
3. von der Maase H, Hansen SW, Roberts JT, Dogliotti L, Oliver T, Moore MJ, Bodrogi I, Albers P, Knuth A, Lippert CM, Kerbrat P, Sanchez Rovira P, Wersall P, Cleall SP, Roychowdhury DF, Tomlin I, Visseren-Grul CM, Conte PF (2000) Gemcitabine and cisplatin versus methotrexate, vinblastine, doxorubicin, and cisplatin in advanced or metastatic bladder cancer: results of a large, randomized, multinational, multicenter, phase III study. J Clin Oncol 18:3068-3077. https://doi.org/10.1200/JCO.2000.18.17. 3068

4. Bamias A, Deliveliotis Ch, Fountzilas G, Gika D, Anagnostopoulos A, Zorzou MP, Kastritis E, Constantinides C, Kosmidis P, Dimopoulos MA (2004) Adjuvant chemotherapy with paclitaxel and carboplatin in patients with advanced carcinoma of the upper urinary tract: a study by the hellenic cooperative oncology group. J Clin Oncol 22:2150-2154. https://doi.org/10.1200/JCO.2004.09. 043

5. Horie S, Oya M, Nangaku M, Yasuda Y, Komatsu Y, Yanagita M, Kitagawa Y, Kuwano H, Nishiyama H, Ishioka C, Takaishi H, Shimodaira H, Mogi A, Ando Y, Matsumoto K, Kadowaki D, Muto S (2018) Guidelines for treatment of renal injury during cancer chemotherapy 2016. Clin Exp Nephrol 22:210-244. https:// doi.org/10.1007/s10157-017-1448-Z

6. Janus N, Thariat J, Boulanger H, Deray G, Launay-Vacher V (2010) Proposal for dosage adjustment and timing of chemotherapy in hemodialyzed patients. Ann Oncol 21:1395-1403. https:// doi.org/10.1093/annonc/mdp598

7. Lichtman SM, Wildiers H, Launay-Vacher V, Steer C, Chatelut E, Aapro M (2007) International society of geriatric oncology (SIOG) recommendations for the adjustment of dosing in elderly cancer patients with renal insufficiency. Eur J Cancer 43:14-34. https://doi.org/10.1016/j.ejca.2006.11.004

8. Birtle A, Johnson M, Chester J, Jones R, Dolling D, Bryan RT, Harris C, Winterbottom A, Blacker A, Catto JWF, Chakraborti P, Donovan JL, Elliott PA, French A, Jagdev S, Jenkins B, Keeley FX, Kockelbergh R, Powles T, Wagstaff J, Wilson C, Todd R, Lewis R, Hall E (2020) Adjuvant chemotherapy in upper tract urothelial carcinoma (the POUT trial): a phase 3, open-label, randomised controlled trial. Lancet 395(10232):1268-1277. https:// doi.org/10.1016/S0140-6736(20)30415-3

9. Chang PY, Dai MS, Ho CL, Yao NS (2013) Administration of gemcitabine and cisplatin in cancer patients with renal failure under hemodialysis. J BUON 18:1058-1061

10. Ide H, Satou A, Hoshino K, Yasumizu Y, Uchida Y, Tasaka Y, Masuda T (2011) Successful management of metastatic urothelial carcinoma with gemcitabine and paclitaxel chemotherapy in a hemodialysis patient. Urol Int 87:245-247. https://doi.org/10. $1159 / 000327511$

11. Matsumoto K (2008) Pharmacokinetics of cisplatin and methotrexate after M-VAC chemotherapy for advanced urothelial cancer in hemodialysis patients. Int J Urol 15:949-950. https://doi.org/ 10.1111/j.1442-2042.2008.02123.x
12. DeConti RC, Toftness BR, Lange RC, Creasey WA (1973) Clinical and pharmacological studies with cis-diamminedichloroplatinum (II). Cancer Res 33:1310-1315

13. Miyakawa M, Sugimoto K, Ohe Y, Masuoka H, Miyahara T (1987) Gan To Kagaku Ryoho 14:2491-2495

14. Ezaki T, Matsumoto K, Morita S, Shinoda K, Mizuno R, Kikuchi E, Oya M (2016) A case of gemcitabine and cisplatin chemotherapy in a patient with metastatic urothelial carcinoma receiving hemodialysis. Clin Genitourin Cancer 14:e413-e416. https://doi. org/10.1016/j.clgc.2016.01.015

15. Himmelstein KJ, Patton TF, Belt RJ, Taylor S, Repta AJ, Sternson LA (1981) Clinical kinetics on intact cisplatin and some related species. Clin Pharmacol Ther 29:658-664. https://doi.org/10. 1038/clpt.1981.91

16. Schellens JH, Ma J, Planting AS, van der Burg ME, van Meerten E, de Boer-Dennert M, Schmitz PI, Stoter G, Verweij J (1996) Relationship between the exposure to cisplatin, DNA-adduct formation in leucocytes and tumour response in patients with solid tumours. Br J Cancer 73:1569-1575. https://doi.org/10.1038/bjc. 1996.296

17. Tokunaga J, Kikukawa H, Nishi K, Kitani K, Fujii J, Honda J, Wada Y, Ueda S, Nakano M (2000) Pharmacokinetics of cisplatin and methotrexate in a patient suffering from advanced ureteral tumor accompanied by chronic renal failure, undergoing combined hemodialysis and systemic M-VAC chemotherapy. Gan To Kagaku Ryoho 27:2079-2085

18. Kiani A, Köhne CH, Franz T, Passauer J, Haufe T, Gross P, Ehninger G, Schleyer E (2003) Pharmacokinetics of gemcitabine in a patient with end-stage renal disease: effective clearance of its main metabolite by standard hemodialysis treatment. Cancer Chemother Pharmacol 51:266-270. https://doi.org/10.1007/ s00280-003-0574-3

19. Masumori N, Kunishima Y, Hirobe M, Takeuchi M, Takayanagi A, Tsukamoto T, Itoh T (2008) Measurement of plasma concentration of gemcitabine and its metabolite dFdU in hemodialysis patients with advanced urothelial cancer. Jpn J Clin Oncol 38:182-185. https://doi.org/10.1093/jjco/hym171

20. Abbruzzese JL, Grunewald R, Weeks EA, Gravel D, Adams T, Nowak B, Mineishi S, Tarassoff P, Satterlee W, Raber MN (1991) A phase I clinical, plasma, and cellular pharmacology study of gemcitabine. J Clin Oncol 9:491-498. https://doi.org/10.1200/ JCO.1991.9.3.491

Publisher's Note Springer Nature remains neutral with regard to jurisdictional claims in published maps and institutional affiliations. 